\title{
Extraction behavior of carrier-free and macro amounts of molybdenum and tungsten from $\mathrm{HCl}$ solution
}

\author{
By K. Ooe ${ }^{1}$, W. Yahagi ${ }^{1}$, Y. Komori ${ }^{1}$, H. Fujisawa ${ }^{1}$, R. Takayama ${ }^{1}$, H. Kikunaga ${ }^{1}$, T. Yoshimura ${ }^{1}$, N. Takahashi ${ }^{1}$, H. Haba ${ }^{2}$, \\ Y. Kudou ${ }^{2}$, Y. Ezaki ${ }^{2}$ and A. Shinohara ${ }^{1, *}$ \\ ${ }^{1}$ Graduate School of Science, Osaka University, Toyonaka, Osaka 560-0043, Japan \\ 2 Nishina Center for Accelerator-Based Science, RIKEN, Wako, Saitama 351-0198, Japan
}

(Received November 27, 2009; accepted in final form November 11, 2010)

\section{Molybdenum / Tungsten / Mononuclear species / Polynuclear species / Solvent extraction / Hydrochloric acid}

Summary. Solvent extraction behavior of carrier-free Mo and $\mathrm{W}$ from $0.1-11 \mathrm{M} \mathrm{HCl}$ into $0.05 \mathrm{M}$ Aliquat 336chloroform solution was investigated and compared with that of macro amounts of Mo and W. The distribution ratios of carrier-free Mo and $\mathrm{W}$ were in good agreement with those of macro amounts of $\mathrm{Mo}$ and $\mathrm{W}$ in $6-11 \mathrm{M} \mathrm{HCl}$, while the extraction efficiencies of carrier-free Mo and $\mathrm{W}$ were different from those of macro amounts of $\mathrm{Mo}$ and $\mathrm{W}$ in $<6 \mathrm{M} \mathrm{HCl}$. Therefore, it appears that the carrier-free as well as macro amounts of Mo and $\mathrm{W}$ form mononuclear species in 6-11 M $\mathrm{HCl}$. The disagreement in $<6 \mathrm{M} \mathrm{HCl}$ is probably due to the formation of polynuclear species of the macro amounts of Mo and $\mathrm{W}$.

\section{Introduction}

The aqueous chemistry of molybdenum (Mo) and tungsten (W) is complicated because these elements form polynuclear species such as $\left[\mathrm{Mo}_{7} \mathrm{O}_{24}\right]^{6-}$ and $\left[\mathrm{W}_{12} \mathrm{O}_{39}\right]^{6-}$ in neutral to acidic solution [1]. These elements are lighter homologues of element 106, seaborgium ( $\mathrm{Sg}$ ) and, therefore, the chemical behavior of these elements is important for investigation of chemical properties of $\mathrm{Sg}$. Because $\mathrm{Sg}$ cannot form polynuclear species due to an extremely low production rate in the order of one atom per hour, an investigation of the chemical behavior of mononuclear Mo and $\mathrm{W}$ species is required for a comparison with that of $\mathrm{Sg}$. It was reported that macro amounts of Mo and $\mathrm{W}$ exist as monomeric oxochloride complexes in concentrated hydrochloric acid $(\mathrm{HCl})(>6-7 \mathrm{M} \mathrm{HCl})$ [2-6]. There is a possibility of existence of polymeric Mo and $\mathrm{W}$ complexes in diluted $\mathrm{HCl}$. In this study, solvent extraction behavior of Mo and $\mathrm{W}$ under the carrier-free condition was investigated by ion-pair extraction from $\mathrm{HCl}$ with Aliquat 336 that extracts anionic species from aqueous solution. Moreover, the results under carrier-free condition were compared with those measured

* Author for correspondence

(E-mail: shino@chem.sci.osaka-u.ac.jp). with macro amounts. Solvent extraction coefficients of Mo and $\mathrm{W}$ obtained under carrier-free condition are much different from those determined with macroscopic amounts in diluted $\mathrm{HCl}$ concentration, while almost the same solvent extraction coefficients for both Mo and $\mathrm{W}$ were obtained in concentrated $\mathrm{HCl}$ solution $(6-11 \mathrm{M} \mathrm{HCl})$. It is found that 6-11 M HCl solution is the best condition for the ion-pair solvent extraction experiment of $\mathrm{Sg}$ in $\mathrm{HCl}$.

\section{Experimental}

In the experiments with carrier-free Mo and $\mathrm{W}, \mathrm{HCl}$ (Wako Pure Chemical Industries, for ultratrace analysis) was diluted to desired concentration with ultrapure water (resistivity of $18.2 \mathrm{M} \Omega \mathrm{cm}$ ). Aliquat 336 was purchased from Sigma Aldrich and was dissolved in chloroform (Kishida Reagents Chemicals, super special grade) to become $0.05 \mathrm{M} \mathrm{Ali-}$ quat 336 in chloroform. Short-lived isotopes, ${ }^{90} \mathrm{Mo}\left(T_{1 / 2}=\right.$ $5.7 \mathrm{~h})$ and ${ }^{173} \mathrm{~W}\left(T_{1 / 2}=7.6 \mathrm{~min}\right)$, were produced in the ${ }^{\text {nat }} \mathrm{Ge}\left({ }^{22} \mathrm{Ne}, x n\right)$ and ${ }^{\text {nat }} \mathrm{Gd}\left({ }^{22} \mathrm{Ne}, x n\right)$ reactions, respectively, using the RIKEN K70 AVF cyclotron. The $300 \mu \mathrm{g} / \mathrm{cm}^{2}$ ${ }^{\text {nat }} \mathrm{Ge}$ and $570 \mu \mathrm{g} / \mathrm{cm}^{2}$ nat $\mathrm{Gd}$ targets were separately prepared by vacuum deposition and electrodeposition, respectively, on beryllium backing foils. The bombarding energies of ${ }^{22} \mathrm{Ne}$ were $120 \mathrm{MeV}$ in the Mo experiment and $118 \mathrm{MeV}$ in the $\mathrm{W}$ experiment. These beam energies were selected to be at about the top of the excitation function in the ${ }^{248} \mathrm{Cm}\left({ }^{22} \mathrm{Ne}, 5 n\right){ }^{265} \mathrm{Sg}$ reaction [7]. Average beam intensities were approximately 100 particle $\mathrm{nA}$ in the Mo experiment and 300 particle $\mathrm{nA}$ in the $\mathrm{W}$ experiment, respectively. Reaction products recoiling out of the target were thermalized in a helium gas flow $(1.8 \mathrm{~L} / \mathrm{min})$, attached to $\mathrm{KCl}$ aerosols generated by sublimation of $\mathrm{KCl}$ powder at $620^{\circ} \mathrm{C}$, and were then transported to a chemistry laboratory. Transported products were deposited on a polyester or Naflon sheet for $5 \mathrm{~min}$ and were then dissolved in $200 \mu \mathrm{L}$ of $0.1-11 \mathrm{M} \mathrm{HCl}$ for Mo or 4-11 M HCl for W. The concentrations of Mo and $\mathrm{W}$ isotopes calculated from their radioactivities were ca. $10^{-13} \mathrm{M}$. The aqueous solution was mixed with an equal volume of the $0.05 \mathrm{M}$ Aliquat 336-chloroform solution, and was then shaken for $3 \mathrm{~min}$ at $25^{\circ} \mathrm{C}$. It was showed that the shaking time of $1 \mathrm{~min}$ was sufficient to attain extraction 
equilibrium of Mo and $\mathrm{W}$ in separate experiments where the shaking times were varied from 1 to $10 \mathrm{~min}$ for Mo and 1 to $5 \mathrm{~min}$ for $\mathrm{W}$. After centrifuging, $160 \mu \mathrm{L}$ aliquots of the aqueous and the organic phase were separated into polypropylene tubes, and then each tubes was subjected to $\gamma$-ray spectrometry using Ge detectors. In the Mo experiments, $\gamma$-ray measurements were carried out after the decay of the byproduct activities (after about $1 \mathrm{~h}$ after the end of deposition of reaction products) because the $259.1 \mathrm{keV} \gamma$-ray from the decay of ${ }^{83 \mathrm{~m}} \mathrm{Y}\left(T_{1 / 2}=2.85 \mathrm{~min}\right){ }^{83 \mathrm{~m}} \mathrm{Sr}\left(T_{1 / 2}=4.95 \mathrm{~s}\right)$ interfered with the detection of ${ }^{90} \mathrm{Mo}\left(E_{\gamma}=257.34 \mathrm{keV}\right)$. Distribution ratios $(D)$ for Mo and $\mathrm{W}$ were calculated with the following equation:

$$
D=\frac{C_{\mathrm{M}, \mathrm{o}}}{C_{\mathrm{M}, \mathrm{a}}}=\frac{A_{\mathrm{o}} V_{\mathrm{a}}}{A_{\mathrm{a}} V_{\mathrm{o}}},
$$

where $C_{\mathrm{M}}$ is the concentration of Mo or $\mathrm{W}, A$ the radioactivity of the metal, and $V$ the volume of aqueous or organic phase. The subscripts a and o denote the aqueous and organic phases, respectively. Each experiment was repeated three times.

In the experiments with macro amounts of Mo and W, $\mathrm{HCl}$ (Kishida Reagents Chemicals, special grade) was diluted to the desired concentration with distilled water. For the preparation of the organic phase, the same reagents as in the carrier-free experiment were used. $\mathrm{Na}_{2}\left[\mathrm{MoO}_{4}\right] \cdot 2 \mathrm{H}_{2} \mathrm{O}$ (Wako Pure Chemical Industries, special grade) and $\mathrm{Na}_{2}\left[\mathrm{WO}_{4}\right] \cdot 2 \mathrm{H}_{2} \mathrm{O}$ (Kishida Reagents Chemicals, special grade) were dissolved in 2-11 M HCl. The concentrations of Mo and $\mathrm{W}$ were approximately $10^{-3} \mathrm{M}$ for Mo and $7 \times 10^{-5}$ to $8 \times 10^{-3} \mathrm{M}$ for $\mathrm{W}$. After the dissolution, the solutions were allowed to stand for some time for polymerization of Mo and W (experimental conditions are summarized in Table 1). $2 \mathrm{ml}$ of the aqueous solution containing Mo or $\mathrm{W}$ were mixed with an equal volume of the $0.05 \mathrm{M}$ Aliquat 336-chloroform solution. These mixtures were then shaken for $3 \mathrm{~min}$ at $25^{\circ} \mathrm{C}$. After centrifuging, the two phases in each sample were separated to determine the metal concentrations in each phase. The aqueous phase was evaporated to dryness, and the residue was dissolved in $1 \mathrm{~mL}$ of $2 \mathrm{M}$ $\mathrm{NaOH}$ solution. The organic phase was mixed with $2 \mathrm{~mL}$ of $2 \mathrm{M} \mathrm{NaOH}$ solution and the mixture was shaken for $10 \mathrm{~min}$

Table 1. Summary of experimental conditions with macro amounts of Mo and W.

\begin{tabular}{ccc}
\hline $\begin{array}{c}\mathrm{HCl} \\
\text { concentration }\end{array}$ & $\begin{array}{c}\text { Time of standing } \\
\text { from dissolution } \\
\text { of the metal }\end{array}$ & $\begin{array}{c}\text { Metal } \\
\text { concentration }\end{array}$ \\
\hline \multicolumn{3}{c}{ Mo } \\
$11.00 \mathrm{M}$ & $<1 \mathrm{~d}$ & $9 \times 10^{-4} \mathrm{M}$ \\
$7.93 \mathrm{M}$ & $7 \mathrm{~d}$ & $9 \times 10^{-4} \mathrm{M}$ \\
$5.95 \mathrm{M}$ & $11 \mathrm{~d}$ & $9 \times 10^{-4} \mathrm{M}$ \\
$3.98 \mathrm{M}$ & $4 \mathrm{~d}$ & $8 \times 10^{-4} \mathrm{M}$ \\
$3.03 \mathrm{M}$ & $<1 \mathrm{~d}$ & $8 \times 10^{-4} \mathrm{M}$ \\
$2.02 \mathrm{M}$ & $10 \mathrm{~d}$ & $8 \times 10^{-4} \mathrm{M}$ \\
& $\mathrm{W}$ & $8 \times 10^{-3} \mathrm{M}$ \\
$11.14 \mathrm{M}$ & $30 \mathrm{~d}$ & $1 \times 10^{-3} \mathrm{M}$ \\
$7.77 \mathrm{M}$ & $4 \mathrm{~d}$ & $1 \times 10^{-4} \mathrm{M}$ \\
$5.74 \mathrm{M}$ & $4 \mathrm{~d}$ & $7 \times 10^{-5} \mathrm{M}$ \\
$3.78 \mathrm{M}$ & $4 \mathrm{~d}$ & \\
\hline
\end{tabular}

to back-extract Mo or W. Metal concentrations in the $\mathrm{NaOH}$ solutions were determined spectrophotometrically by a thiocyanate method [8]. The sample solution was prepared by adding $200 \mu \mathrm{L}$ of $3.2 \mathrm{M} \mathrm{NH}_{4} \mathrm{SCN}$ (for Mo) or $5 \mathrm{M} \mathrm{NH}_{4} \mathrm{SCN}$ (for $\mathrm{W}$ ) solution to $1 \mathrm{~mL}$ of $2 \mathrm{M} \mathrm{NaOH}$ solutions, and then it was diluted to $5 \mathrm{~mL}$ with $0.2 \mathrm{M} \mathrm{SnCl}_{2}$ in $2 \mathrm{M} \mathrm{HCl}$ (for $\mathrm{Mo}$ ) or $0.2 \mathrm{M} \mathrm{SnCl}_{2}$ in $8 \mathrm{M} \mathrm{HCl}$ (for W) solution. Each solution was allowed to stand for $30 \mathrm{~min}(\mathrm{Mo})$ or $1 \mathrm{~h}(\mathrm{~W})$ to let the color develop. Absorbances of these solutions were measured at $465 \mathrm{~nm}$ and $402.5 \mathrm{~nm}$ for Mo and $\mathrm{W}$, respectively. Each experiment was repeated at least three times.

\section{Results and discussion}

The results of our extraction experiments of carrier-free and macro amounts of Mo and $\mathrm{W}$ are shown in Figs. 1 and 2, respectively. $D$ values for carrier-free Mo and $\mathrm{W}$ increase with an increase of $\mathrm{HCl}$ concentration, indicating that anionic chloride complexes of Mo and $\mathrm{W}$ such as $\left[\mathrm{MO}_{2} \mathrm{Cl}_{3}\right]^{-}$ $(\mathrm{M}=\mathrm{Mo}$ and $\mathrm{W})[2,4,9]$ are formed. The extraction efficiency of Mo is higher than that of W under the studied conditions. These results are in good agreement with previously reported results of anion exchange experiments [10,11]. Tungsten in carrier-free condition is almost not extracted in $4 \mathrm{M} \mathrm{HCl}$, suggesting that $\mathrm{W}$ exists as cationic and/or neutral species under these conditions in the $\mathrm{HCl}$.

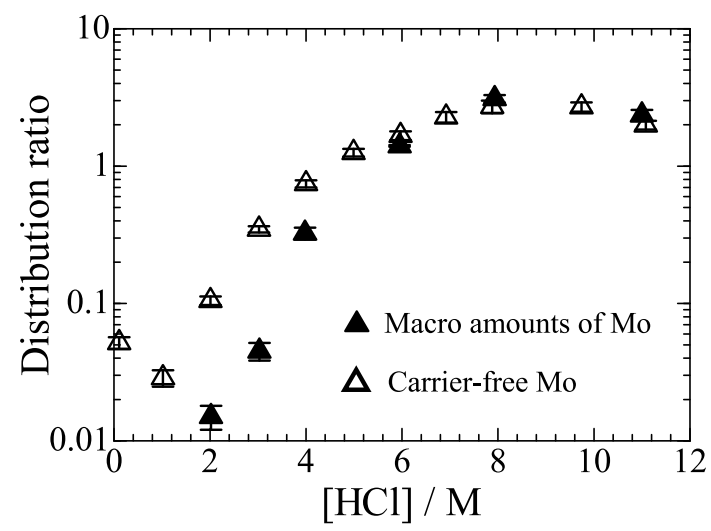

Fig. 1. Extractions of carrier-free and macro amounts of Mo from hydrochloric acid with $0.05 \mathrm{M}$ Aliquat 336-chloroform solution.

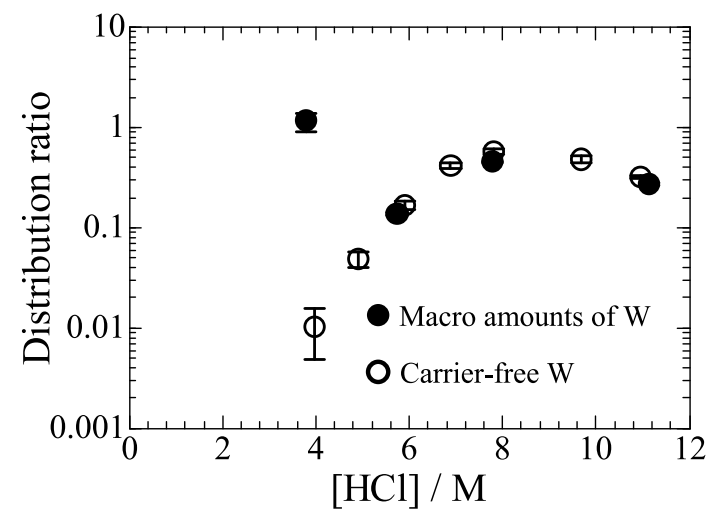

Fig. 2. Extractions of carrier-free and macro amounts of W from hydrochloric acid with $0.05 \mathrm{M}$ Aliquat 336-chloroform solution. 
$D$ values of carrier-free Mo are higher than the ones with macro amounts of $\mathrm{Mo}$ in $<6 \mathrm{M} \mathrm{HCl}$. It was reported that cationic dimer species of $\mathrm{Mo}$, such as $\left[\mathrm{Mo}_{2} \mathrm{O}_{5}\left(\mathrm{H}_{2} \mathrm{O}\right)_{6}\right]^{2+}$, which are not extracted with Aliquat 336, is formed in $<6 \mathrm{M} \mathrm{HCl}[12,13]$ in addition to other cationic monomers and neutral species such as $\mathrm{MoO}_{2}^{2+}$ and $\mathrm{MoO}_{2} \mathrm{Cl}_{2}[14,15]$. Therefore, the steeper decrease in $D$ value of macro amounts of Mo compared to carrier-free condition when going to lower $\mathrm{HCl}$ concentrations is probably attributed to the formation of cationic dimer species of $\mathrm{Mo}$ in $<6 \mathrm{M} \mathrm{HCl}$. Macro amounts of $\mathrm{W}$ are extracted with a much higher distribution ratio as compared with carrier-free $\mathrm{W}$ in $4 \mathrm{M} \mathrm{HCl}$. Presumably, macro amounts of $\mathrm{W}$ form anionic polynuclear species in $4 \mathrm{M} \mathrm{HCl}$ while carrier-free $\mathrm{W}$ forms cationic and/or neutral species in $4 \mathrm{M} \mathrm{HCl}$. These results strongly suggest that the chemical species of macro amounts of Mo and $\mathrm{W}$ in $<6 \mathrm{M} \mathrm{HCl}$ are different from those of carrier-free Mo and W.

On the other hand, the $D$ values of carrier-free Mo and $\mathrm{W}$ are in good agreement with those of macro amounts of Mo and $\mathrm{W}$, respectively, in 6-11 $\mathrm{M} \mathrm{HCl}$. As described above, it was reported that macro amounts of Mo and $\mathrm{W}$ exist as monomeric oxochloride complexes in concentrated $\mathrm{HCl}$. The fact that the $D$ values are almost the same in both macroscopic and carrier-free conditions suggests that the carrier-free as well as macro amounts of Mo and W would form the mononuclear species in 6-11 M HCl. Therefore, we conclude that the ion-pair extraction of Mo and $\mathrm{W}$ from 6-11 M HCl with Aliquat 336 is available for the comparison with that of $\mathrm{Sg}$, and information on the formation of anionic chloride complexes of $\mathrm{Sg}$ can be obtained from this extraction condition. It is reported that the nuclear reaction products such as Po produced from $\mathrm{Pb}$ impurities in the $\mathrm{Cm}$ target disturb the detection of $\alpha$-lines of ${ }^{265} \mathrm{Sg}$ [16], however, these reaction products are observed at least in either aqueous or organic phase in the solvent extraction experiments. Therefore, the chemical studies of Sg should be performed with a physical separator such as GARIS [17].

\section{Conclusion}

Solvent extraction experiments with carrier-free and macro amounts of Mo and $\mathrm{W}$ from $0.1-11 \mathrm{M} \mathrm{HCl}$ into $0.05 \mathrm{M}$ Aliquat 336-chloroform solution were carried out, and these results were utilized for the discussion of experimental conditions under which the extraction behavior of Mo and $\mathrm{W}$ can be compared to that of $\mathrm{Sg}$. The extraction behavior of carrier-free Mo and $\mathrm{W}$ corresponded to that of macro amounts of $\mathrm{Mo}$ and $\mathrm{W}$ in 6-11 M HCl. This result shows that Mo and $\mathrm{W}$ exist as mononuclear species in both macro amount and carrier-free conditions in 6-11 M HCl. In conclusion, the present extraction system in $6-11 \mathrm{M} \mathrm{HCl}$ is applicable to study mononuclear species of $\mathrm{Sg}$. Extraction efficiencies of carrier-free Mo and $\mathrm{W}$ are different from those of macro amounts of $\mathrm{Mo}$ and $\mathrm{W}$ below $6 \mathrm{M} \mathrm{HCl}$, indicating the formation of polynuclear species in experiments with macro amounts of Mo and W. We will further investigate the chemical species of carrier-free Mo and $\mathrm{W}$ in $<6 \mathrm{M}$ $\mathrm{HCl}$ for more detailed chemical studies of $\mathrm{Sg}$ in $4 \mathrm{M} \mathrm{HCl}$, where the extraction behavior of Mo is quite different from that of $\mathrm{W}$.

Acknowledgment. We thank the crew of RIKEN K70 AVF cyclotron for their invaluable assistance in the course of these experiments. This work is supported by the Japan Society for the Promotion of Science (JSPS) Research Fellowship for Young Scientists.

\section{References}

1. Baes, C. F., Mesmer, R. E.: The Hydrolysis of Cations. John Wiley, New York (1976).

2. Rohwer, E. F. C. H., Cruywagen, J. J.: Monomeric chloro-complexes of molybdenum(VI). J. South Afr. Chem. Inst. 19, 11 (1966).

3. Nelidow, I., Diamond, R. M.: The solvent extraction behavior of inorganic compounds: molybdenum(VI), J. Phys. Chem. 59, 710 (1955).

4. Sato, T., Sato, K.: Liquid-liquid extraction of tungsten (VI) from hydrochloric acid solution by neutral organophosphorus compounds and high molecular weight amines, Hydrometallurgy 37, 253 (1995).

5. De, A. K., Rahaman, M. S.: Liquid-liquid extraction of tungsten ${ }^{\mathrm{VI}}$ with tributyl phosphate. Talanta 11, 601 (1964).

6. Haas, I., Jäger, S., Katscher, H., Schneider. D., Wagner, J.: Gmelin Handbook of Inorganic and Organometallic Chemistry. $8^{\text {th }}$ Edn., Molybdenum Syst. No. 53, Suppl. Vol. B 6, Springer-Verlag (1990), p. 106.

7. Düllmann, Ch. E., Tüler, A.: ${ }^{248} \mathrm{Cm}\left({ }^{22} \mathrm{Ne}, x n\right){ }^{270-x} \mathrm{Sg}$ reaction and the decay properties of ${ }^{665} \mathrm{Sg}$ reexamined. Phys. Rev. C 77, 064320 (2008).

8. Sandell, E. B.: Colorimetric Determination of Traces of Metals. $3^{\text {rd }}$ Edn., Interscience, New York (1959).

9. Kraus, K. A., Nelson, F., Moore, G. E.: Anion-exchange studies. XVII. Molybdenum(VI), tungsten(VI) and uranium(VI) in $\mathrm{HCl}$ and HCl-HF solutions. J. Am. Chem. Soc. 77, 1972 (1955).

10. Caletka, R., Krivan, V.: Anion-exchange behavior of some elements in HF-HCl medium. J. Radioanal. Nucl. Chem 142, 373 (1990).

11. Huffman, E. H., Oswalt, R. L., Williams, L. A.: Anion-exchange separation of molybdenum and technetium and of tungsten and rhenium. J. Inorg. Nucl. Chem. 3, 49 (1956).

12. Diamond, R. M.: The solvent extraction behavior of inorganic compounds. III. Variation of the distribution quotient with metal ion concentration. J. Phys. Chem. 61, 75 (1957).

13. Coddington, J. M., Taylor, M. J.: Molybdenum-95 nuclear magnetic resonance and vibrational spectroscopic studies of molybdenum (VI) species in aqueous solutions and solvent extracts from hydrochloric and hydrobromic acid: evidence for the complexes $\left[\mathrm{Mo}_{2} \mathrm{O}_{5}\left(\mathrm{H}_{2} \mathrm{O}\right)_{6}\right]^{2+},\left[\mathrm{MoO}_{2} \mathrm{X}_{2}\left(\mathrm{H}_{2} \mathrm{O}\right)_{2}\right](\mathrm{X}=\mathrm{Cl}$ or $\mathrm{Br})$, and $\left[\mathrm{MoO}_{2} \mathrm{Cl}_{4}\right]^{2-}$. J. Chem. Soc. Dalton Trans. 41 (1990).

14. Hoenes, H. J., Stone, K. G.: Analytical chemistry of $\alpha$-benzoinoxime complexes of molybdenum, tungsten and vanadium. Talanta 4, 250 (1960).

15. Neumann, H. M., Cook, N. C.: Species of molybdenum (VI) in hydrochloric acid. J. Am. Chem. Soc. 79, 3026 (1957).

16. Türler, A., Dressler, R., Eichler, B., Gäggeler, H. W., Jost, D. T., Schädel, M., Brüchle, W., Gregorich, K. E., Trautmann, N., Taut, S.: Decay properties of ${ }^{265} \mathrm{Sg}(Z=106)$ and ${ }^{266} \mathrm{Sg}(Z=106)$. Phys. Rev. C 57, 1648 (1998).

17. Haba, H., Kaji, D., Komori, Y., Kudou, Y., Moromoto, K., Morita, K., Ooe, K., Ozeki, K., Sato, N., Shinohara, A., Yoneda, A.: RIKEN gas-filled recoil ion separator (GARIS) as a promising interface for superheavy element chemistry - production of element $104,{ }^{261} \mathrm{Rf}$, using the GARIS/gas-jet system. Chem. Lett. 38, 426 (2009). 